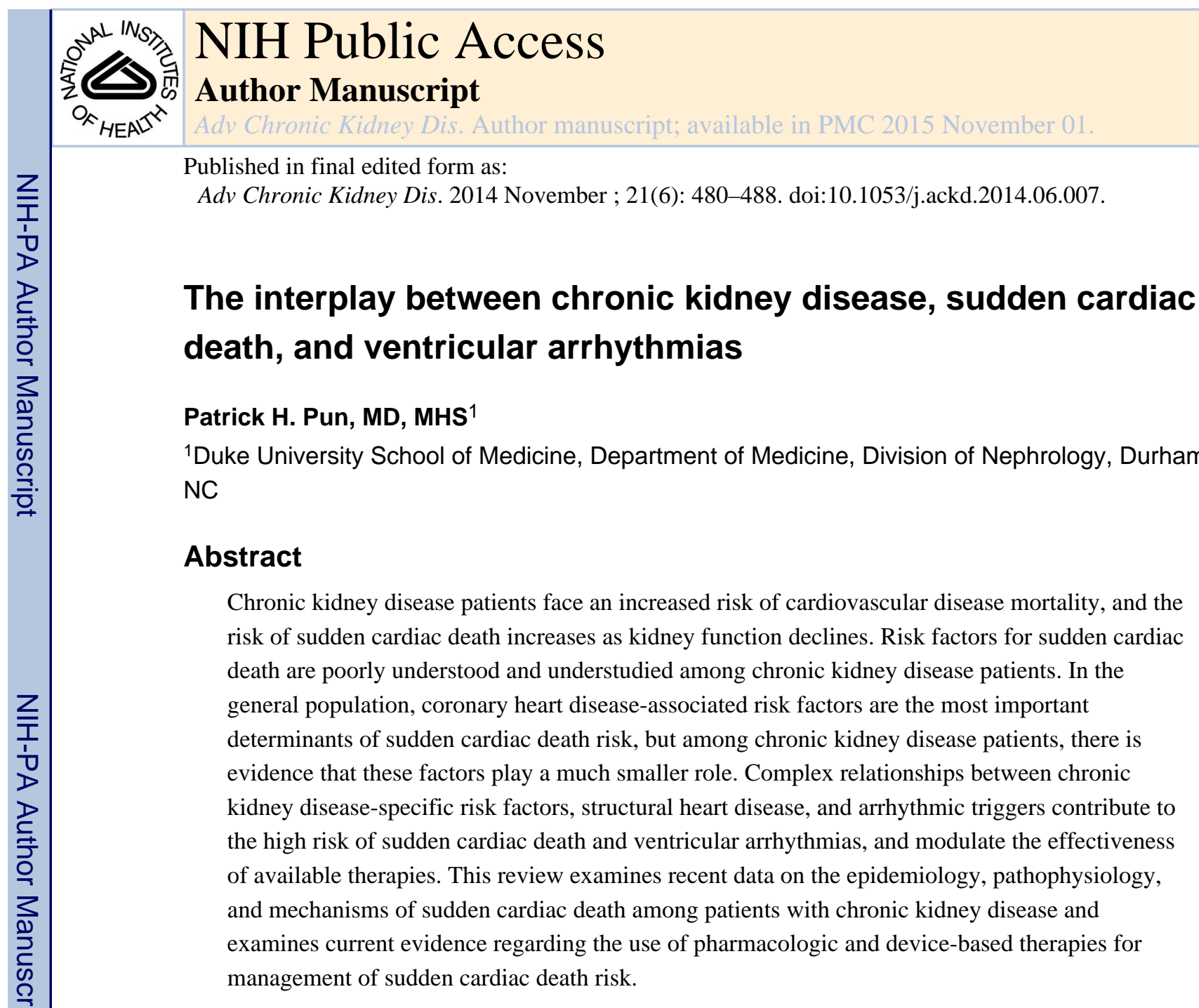

\title{
Introduction
}

Chronic kidney disease (CKD) affects more than 20 million Americans; compared to the general population, these patients have a four to 20 times greater risk of sudden cardiac death (SCD). (1) As kidney function declines, sudden cardiac death risk proportionally increases. (2) Although coronary artery disease-related risk factors explain sudden cardiac death risk in the general population, in CKD, these factors incompletely explain increased risk. (2) Accordingly, there is an increasing body of evidence suggesting that targeting traditional cardiovascular risk factors among CKD patients is an ineffective strategy to address the high risk of cardiovascular mortality. Thus, the purpose of this review is to highlight what is known and what remains to be understood about the relationships among

(C) 2014 by the National Kidney Foundation, Inc. All rights reserved.

Address for correspondence: Patrick H. Pun, MD, MHS, Duke University Medical Center, P.O. Box 2747, Durham, NC 27710, patrick.pun@duke.edu, Telephone: 919-660-6865, Fax: 919-684-4476.

Author Disclosure: No relevant conflicts of interest to report.

Publisher's Disclaimer: This is a PDF file of an unedited manuscript that has been accepted for publication. As a service to our customers we are providing this early version of the manuscript. The manuscript will undergo copyediting, typesetting, and review of the resulting proof before it is published in its final citable form. Please note that during the production process errors may be discovered which could affect the content, and all legal disclaimers that apply to the journal pertain. 
$\mathrm{CKD}$, ventricular arrhythmias, and sudden death, and to provide insights into management of this problem based on the current state of evidence.

\section{Epidemiology and Definition of Sudden Cardiac Death}

SCD is an important cause of death among all patients with chronic kidney disease (CKD). The specific risk of SCD among patients with CKD stages 3-5 has been explored. Secondary analyses of subjects with moderate CKD enrolled in the MADIT-II and COMPANION implantable defibrillator trials have reported an incremental risk of SCD with decreasing baseline glomerular filtration rate $(3,4)$. A linear relationship with a negative slope between estimated glomerular filtration rate and SCD risk has also been observed among a large population-based prospective cohorts with CKD and significant coronary heart disease (2), postmenopausal women with coronary heart disease (5), and elderly persons without clinically significant cardiac disease (6). (Figure 1) In these studies, the increased risk of SCD associated with CKD could not be accounted for by the degree of measured cardiac or other comorbidities.

In patients with end stage kidney disease (ESKD) treated with either hemo- or peritoneal dialysis, the risk of SCD is alarming. According to United States Renal Data System (USRDS) registry data, SCD accounts for about 1 of every 4 deaths among both hemodialysis and peritoneal dialysis patients at an annual rate of 6-7\% $(7,8)$. Recent updated estimates from the USRDS suggest a modest improvement in the annual SCD rate among prevalent dialysis patients, now reported as 5.5\% (9) The first nine months after a patient initiates a hemodialysis regimen appears to be a particularly high-risk period for SCD. (10) Survival following a sudden cardiac arrest among ESKD patients is universally poor, with a 6-month survival between 3-11\% (11-14). It is important to acknowledge that data on SCD epidemiology is largely derived from data contained in large population registries which may be prone to misclassification due to lack of a systematic adjudication process and a precise definition of SCD. However, adjudicated data from randomized clinical trials and several prospective hemodialysis and peritoneal dialysis cohorts are largely in agreement with registry data regarding the relative contribution of sudden death to all-cause mortality (22-26\%) among dialysis-maintained ESKD patients (15-18). International and regional comparison of SCD rates has not been systematically evaluated, but multinational data from the Dialysis Outcomes and Practice Patterns (DOPPS) registry suggests that sudden death accounts for the highest proportion of hemodialysis deaths in the United States (33\%) whereas lower proportions were observed in Japan (23\%), Australia/New Zealand (19\%) and Canada (18\%). (19) The relationship between decreased SCD rates in these countries and differences in dialysis practices, particularly, increased utilization of frequent and nocturnal hemodialysis is an intriguing observation that has not yet been examined.

\section{Definition of sudden cardiac death in CKD patients}

As discussed above, it is important to acknowledge that SCD rates that are reported from large, population-based registries are closely tied to how SCD is defined. The most widely accepted definition of SCD is death from an unexpected circulatory arrest, occurring within 
an hour of symptom onset, or an unwitnessed, unexpected death in patients known to be well within the past 24 hours without an obvious non-cardiac cause. (20-22) Several factors make application of this definition difficult among CKD patients. First, as with other populations, most sudden deaths among CKD patients are unwitnessed and clinical information collected around the time is very often limited, making exclusion of a non-cardiac cause of sudden death difficult. (23) Second, determining the sudden nature of death is problematic in CKD patients, particularly among ESKD patients. ESKD patients are often chronically ill, carry a high burden of comorbidities, and are frequently hospitalized and receive care in other health care facilities. Because of these factors, there is lack of consistency in how SCD has been defined in ESKD patients in existing literature. For example, cardiac arrests occurring in the hospital, in the setting of hyperkalemia, during withdrawal from dialysis, and as a consequence of a missed dialysis treatment have been included as SCD in some studies, whereas other studies have excluded these as SCD. $(19,24,25)$ If patient outcomes are to improve, more uniform definitions of SCD when assessing cause of death will be critical to identifying key risk factors and evaluating interventions.

\section{Pathophysiology of SCD in CKD patients}

SCD pathophysiology usually involves the combination of vulnerable myocardial substrate with a transient arrhythmic trigger, leading to a terminal arrhythmia. (26) In the general population, ischemic cardiomyopathy with reduced left ventricular ejection fraction is the structural heart disease that accounts for the vast majority of SCD events. (26) Acute ischemia from coronary plaque rupture induces disordered ventricular conduction in diseased myocardium, and ventricular tachyarrhythmia (ventricular fibrillation or sustained ventricular flutter) is the terminal arrhythmia in over $80 \%$ of cases. $(26,27)$ Thus, therapies that prevent or slow the development of coronary heart disease and therapies using defibrillation to convert ventricular arrhythmias to sinus rhythm have been shown to be effective SCD management approaches in the general population.

SCD pathophysiology in CKD patients has not been clearly established, but current evidence points to important fundamental differences. These differences include the pathology of coronary artery disease (CAD) and underlying structural heart disease, a unique set of arrhythmic triggers, and uncertainty regarding the final common arrhythmic pathway among victims of SCD with CKD. It is important to note that most studies investigating mechanisms of SCD in CKD patients have been conducted in patients with ESKD, with only a few studies among patients with less advanced CKD.

\section{Coronary Artery Pathology, Structural Heart Disease and SCD in CKD patients}

In contrast to the general population, in which $\mathrm{CAD}$ follows a general pattern of lipid-laden intimal atherosclerotic lesions, CAD in CKD patients follows a pattern of diffuse multivessel involvement with arterial stiffening and calcification in the medial arterial layers. (28) Arterial media calcification has been linked to overall cardiovascular mortality in hemodialysis patients, but not to SCD risk specifically. (29) These differences in underlying pathology may explain the reduced value of traditional cardiovascular risk factors such as 
cholesterol levels (30), obesity (31), and blood pressure (32) in predicting mortality and cardiovascular events among CKD patients.

Ischemic cardiomyopathy with reduced ejection fraction accounts for a minority $(<30 \%)$ of structural heart disease seen among victims of SCD with CKD. (25) Echocardiography in a cohort of 1254 consecutive incident hemodialysis patients revealed that only $13 \%$ had left ventricular ejection fraction $<50 \%$; (33) in the CRIC study, a large prospective cohort of patients with moderate CKD, only $18 \%$ of patients had left ventricular ejection fraction < $50 \%$. (34) Ejection fraction and CHF severity also did not explain increased SCD risk among CKD patients in an observational study of 19,000 patients who underwent cardiac catheterization; this study also did not find an association between the severity of coronary artery lesions and SCD risk in the CKD population. (35)

Diastolic dysfunction due to left ventricular hypertrophy, instead of left ventricular systolic dysfunction, predominates in CKD patients who experience SCD. Two case series of hemodialysis patients who experienced sudden cardiac arrest found that left ventricular hypertrophy was seen in more than $70 \%$ of cases. $(25,36)$ An increase in left ventricular mass index over time was found to be the most potent predictor of SCD death risk in 10-year observational study of hemodialysis patients. (37) MRI studies of hemodialysis patients describe a diffuse pattern of myocardial fibrosis underlying left ventricular hypertrophy, (38, 39) and this pattern occurs in the absence of significant coronary artery disease. (22) This may be the result of multiple factors uniquely present in CKD patients, such as microvessel disease and capillary deficit (capillary/myocyte mismatch) (40), disorders of mineral metabolism and secondary hyperparathyroidism (41), and repetitive myocardial injury from reduction in myocardial perfusion during dialysis and dialysis-induced myocardial "stunning". (42)

\section{Arrhythmic triggers in CKD patients}

Patients with CKD, especially those who are maintained on hemodialysis, are exposed to a wide array of potential arrhythmic triggers. The finding that SCD occurs most frequently on hemodialysis days, especially on the first hemodialysis day after the long dialysis-free weekend for patients on a thrice-weekly treatment schedule, suggests that factors related to the hemodialysis procedure trigger fatal arrhythmias. $(25,43)$ Observational studies have identified both hyperkalemia and hypokalemia (44), exposure to low potassium and calcium dialysate $(12,44)$, and rapid ultrafiltration rate (45-47) with an increased risk of cardiovascular mortality and SCD. Over the course of a dialysis treatment, electrocardiogram (ECG) measures related to ventricular repolarization such as QT interval dispersion and QT interval prolongation worsen. (48) These ECG changes have been shown to be influenced by exposure to low calcium and potassium during hemodialysis, and have been independently associated with cardiovascular mortality in dialysis patients, although they are yet to be specifically linked to a SCD risk. (49) These findings suggest that perturbations in potassium and calcium are critical risk factors for SCD in dialysis patients; among patients with moderate stage 3-4 CKD, no study to date has examined the role of serum electrolyte levels in SCD risk. (25) If similar relationships are seen among moderate 
CKD patients, more careful management of serum electrolyte concentrations could have an important impact on SCD risk.

Recent discussions have also brought to light the potential importance of alkalosis and dialysate bicarbonate concentrations in the pathogenesis of SCD among hemodialysis patients. Bicarbonate concentrates are mixed with acetate (metabolized by the liver to bicarbonate) in the dialysate to manage metabolic acidosis that is common among hemodialysis patients. However, higher dialysate bicarbonate concentrations have been associated with hypokalemia, hemodynamic instability and QTc prolongation. (50-52) A high prevalence $(54 \%)$ of metabolic alkalosis (serum bicarbonate $>30 \mathrm{mEq} / \mathrm{L}$ ) was observed in a case series of 50 hospitalized hemodialysis patients, all of whom were treated with dialysate containing $35 \mathrm{mEq} / \mathrm{L}$ of bicarbonate and $8 \mathrm{mEq} / \mathrm{L}$ of acetate (total $43 \mathrm{mEq} / \mathrm{L}$ base). (52) A recent study using data from DOPPS registries found a significant association between serum bicarbonate level and all-cause mortality; however, the increased mortality was primarily driven by infection-related complications rather than cardiovascular causes. (53) In response to this concern and an unpublished report of an increased risk of cardiac arrest associated with high predialysis serum bicarbonate levels within a dialysis organization, the US Food and Drug Administration released a warning alerting clinicians to account for the contribution of acetate to the total dialysate buffer concentration when considering the appropriate dialysis prescription. This is a prudent consideration, and it is intuitive to avoid high buffer levels among patients who are already alkalotic; however, it is premature to make recommendations regarding the optimal dialysate or serum bicarbonate concentration on the basis of data currently available.

Observations of racial differences in tolerance to hyper- and hypokalemia among CKD patents suggest that genetic factors may play a role in determining susceptibility to arrhythmic triggers. (54) While common variants in genetic loci encoding cardiac ion channels have been identified as important modulators of SCD risk in the general population, (55) no genetic susceptibility studies have ever been conducted in populations enriched with CKD patients. Identifying genetic variants that predict SCD risk in CKD patients could help identify novel SCD pathways and serve as non-invasive risk markers for targeted therapy.

\section{SCD and Terminal Arrhythmias in CKD patients}

Ventricular tachyarrhythmia is the final common pathway for the majority of SCD in the non-CKD population, and is an important indicator of a primary cardiac etiology of sudden death. Whether or not sudden deaths in CKD patients are predominantly the result of ventricular tachyarrhythmia is unclear, as there is a lack of comprehensive prospective cardiac monitoring data in CKD patients. A recent 24-hour Holter-monitoring study of 111 patients with moderate CKD found that $35 \%$ experienced ventricular arrhythmias (predominantly ventricular extra-systoles), and that left ventricular mass index was the strongest predictor of arrhythmias. (56) A retrospective study of 75 hemodialysis patients who were prescribed a wearable cardioverter defibrillator and suffered a cardiac arrest event found that ventricular tachyarrhythmias accounted for $79 \%$ of events. (57) A rat model of progressive CKD demonstrated that the hearts of CKD rats had lower induction thresholds 
for ventricular fibrillation with loss of repolarization reserve and altered cardiac calcium homeostasis. (58) These studies are balanced against other studies which report that as few as $19 \%$ of cardiac arrest events in hemodialysis patients are due to ventricular arrhythmias, whereas bradycardia, asystole and pulseless electrical activity were seen more commonly. $(12,25,59)$ This pattern of terminal arrhythmias suggest that other mechanisms, distinct from the cardiovascular system itself, may be important causes of sudden death in ESKD patients. Unique dialysis-specific complications such as hyperkalemia, air embolism, exsanguination from vascular access, and other non-cardiac mechanisms could easily be mistaken for a primary cardiac event. A small autopsy series of Japanese dialysis patients who were victims of sudden death found stroke as the most frequent etiology (25.8\%), followed by cardiac disease (19\%), and infectious disease (17.2\%). (60) This disturbing lack of clarity on the underlying terminal arrhythmias involved in SCD events in CKD patients should fuel further investigation into characterization of SCD, since non-ventricular arrhythmias would not be expected to respond to traditional resuscitative measures involving defibrillation. The advent of a new generation of continuous, leadless arrhythmia monitors including miniaturized implantable loop monitors and wearable monitors with extended continuous monitoring capabilities should offer opportunities for further study. (61)

\section{Prevention and Management of SCD Risk}

Unfortunately, there have been no randomized clinical trials of interventions to reduce SCD in CKD patients. Definitive studies are needed to develop effective strategies to manage the problem of SCD, but recommendations can be developed based on existing evidence from observational studies. As with investigations into the pathophysiology of SCD, studies of therapies for SCD have been predominantly been conducted among patients receiving chronic dialysis.

Given the heightened risk of SCD in the CKD population and the abysmal long-term survival rate following a cardiac arrest, (62) primary prevention of SCD should be a major priority. Efforts to identify high-risk patients are hampered by the fact that most of the risk factors identified by prior studies have only weak associations with SCD in small cohorts of patients. Even though potent SCD risk predictors in non-CKD populations such as low ejection fraction have also been associated with SCD in some CKD populations such as peritoneal dialysis patients, (18) the predominance of diastolic rather than systolic heart dysfunction among CKD patients greatly reduces its utility in risk stratification. Biomarkers which have been associated with increased risk of SCD include inflammatory markers (IL-6 (17), C-reactive protein (17), and adiponectin (63)) and markers of nutrition (serum albumin (17), pre-dialysis serum creatinine (64)). Using data from the hemodialysis (HEMO) study, a SCD prediction model was developed using available baseline variables. Using a forwardselection process to select variables with significant associations, the final model included age, diabetes, peripheral vascular disease, ischemic heart disease, serum creatinine, and serum alkaline phosphatase, and model discrimination and calibration were good. (65) Unfortunately, this prediction model has not been validated in other populations, and it is unclear how risk factors identified by other studies mentioned above should be incorporated and weighted in determining overall risk. (66) 
In spite of these deficiencies, some general assumptions can reasonably be made about the profile of the high-risk CKD patients based on demographic, comorbid, clinical, and behavioral risk factors. For ESKD patients, the first months following initiation of hemodialysis appears to be a period of increased hazard; risk accumulates with advanced dialysis vintage for both hemodialysis and peritoneal dialysis patients alike. (24) Dialysis patients who are prone to large interdialytic weight gains, extremes of serum potassium level, and those who fall far out of the desired target ranges for mineral metabolism and nutrition also form the general profile of the high risk patient. $(44,67)$ For all CKD patients, victims of SCD are commonly diabetic and have a history of arrhythmias and pre-existing heart disease. $(24,35)$

\section{Pharmacologic Agents and SCD prevention}

A potential strategy to reduce SCD events would be to target high-risk CKD patients for prevention using cardiovascular medications. Beta-adrenergic blockers have been shown to reduce SCD after myocardial infarction, but their utility for this purpose in CKD patients remains unclear. Hemodialysis patients prescribed beta-blockers were observed to have improved survival after cardiac arrest (11), and a randomized study of carvedilol among 114 hemodialysis patients with dilated cardiomyopathy showed an overall $24 \%$ reduction in mortality at 2 years, and a trend towards a significant reduction in SCD. (68) However, in a secondary analysis of the HEMO study, beta-blocker use was not associated with a decreased risk of SCD. (69) More recently, a randomized study of 200 hemodialysis patients compared the efficacy of the beta-blocker atenolol with lisinopril to reduce left ventricular hypertrophy. (70) Although no differences in change in left ventricular mass were seen between the intervention groups, patients treated with atenolol had significantly fewer combined cardiovascular events and heart failure hospitalizations, resulting in early termination of the study. There were fewer arrhythmic and cardiac arrest events in the atenolol arm, although the number of events was too small to establish statistical significance.

The Study of Heart and Renal Protection (SHARP) trial suggests that cholesterol-lowering medications provide overall benefit among CKD patients. (71) In SHARP, patients with CKD (including two-thirds of patients with moderate CKD and one-third of patients on dialysis) who were treated with simvastatin and ezetimibe experienced significantly fewer cardiovascular events than patients who did not receive cholesterol-lowering medications. The main reduction in the composite cardiovascular event rate was attributed to a decreased need for coronary revascularization; there was no significant reduction in all-cause mortality among treated patients. (71) It is important to note that the overall benefit was driven primarily by the effect among patients with moderate CKD, with no significant benefit detected among dialysis patients, although this could be attributed to a lack of statistical power in this smaller subgroup. However, two previous adequately-powered studies also failed to uncover a significant cardiovascular benefit from cholesterol-lowering statin medications among hemodialysis patients: the 4D (atorvastatin) and AURORA (rosuvastatin) trials. $(16,72)$ 
The cardiovascular benefit of renin-angiotensin-aldosterone system blockers on cardiovascular outcomes has been investigated in patients with moderate CKD, but has been poorly studied in ESKD patients on dialysis. Subgroup analyses of the Heart Outcomes and Prevention Evaluation study showed that treatment with ramipril reduced cardiovascular mortality among patients with mild to moderate CKD. (73) However, in another study, the angiotensin receptor blocker losartan did not influence cardiovascular and overall mortality among CKD patients with diabetic nephropathy. (74) A randomized controlled trial of fosinopril and a more recent controlled trial of olmesartan among hypertensive chronic hemodialysis patients both failed to demonstrate a reduction of major cardiovascular events or all-cause mortality. $(75,76)$ A meta-analysis of randomized controlled trials of ACE inhibitors and angiotensin receptor blockers in hemodialysis patients confirmed the lack of a significant effect of these medications on cardiovascular events and mortality; however, a significant reduction in left ventricular mass was observed, leaving open the possibility that these medications might have a beneficial effect on cardiovascular events in a larger, adequately powered trial. (77)

Taken together, these observations suggest at the very least that classes of medications that effectively lower cardiovascular risk in the general population have a more muted effect in patients with CKD. Further well-designed clinical trials are needed to assess the benefit of these medication classes before routine use for SCD reduction can be recommended.

\section{Management of Dialysis-Associated Arrhythmic Triggers}

Greater attention to detail in determining the dialysis prescription, and avoidance of large electrolyte and fluid volume shifts is critical to reduce the risk of SCD in patients with ESKD. Elimination or limited use of low or no potassium dialysate from the outpatient dialysis center is supported by three large cohort studies. $(12,19,44)$ It is important to note that in these studies, patients prescribed low potassium dialysate had mean predialysis serum potassium levels in the normal range, suggesting that more careful adjustment of dialysate potassium concentration in response to laboratory data may be an important step to reduce the risk of SCD. The use of a dialysate potassium modeling, in which the serum to dialysate potassium gradient is maintained at a constant level throughout treatment to reduce large potassium shifts, has been shown to reduce the incidence of premature ventricular contractions during dialysis. (78) Avoidance of low calcium dialysate and reduction in the serum-dialysate calcium gradient has also been associated with a significant reduction in the risk of SCD. (79) Making efforts to reduce interdialytic weight gain and ultrafiltration rates is supported by consistent associations between higher ultrafiltration rates and cardiac events. (47) Evolving data also supports the reduction of dialysate to serum sodium gradient as a means to reduce weight gain and large ultrafiltration targets. (80) There is renewed interest in dialysate cooling as a means to reduce intradialytic hypotension and repetitive ischemic myocardial injury. A recent study suggests that reducing dialysate temperature to two degrees Celsius below body temperature reduces the occurrence of dialysis induced myocardial wall motion abnormalities, which have been associated with an increased risk of cardiac death. (81) Reductions in left ventricular mass that were observed in clinical trials of frequent and long slow hemodialysis are cause for optimism that these modalities may 
improve the tolerability of the dialysis procedure and prove beneficial in preventing SCD.

\section{Implantable Cardioverter Defibrillators}

The role of implantable cardioverter defibrillators (ICDs) for prevention in SCD in CKD patients is controversial. ICDs are a proven but expensive therapy to reduce SCD and overall mortality in patients at risk without kidney disease. Although it seems appealing to manage the epidemic of SCD in CKD patients with this therapy, there is a lack of evidence supporting safety and efficacy of ICDs. Randomized trials of ICDs have excluded patients with advanced CKD, but secondary analyses of trial data demonstrate reduced benefit of ICDs among patients with mild to moderate CKD. A recent meta-analysis of patient-level data from three randomized trials of primary prevention ICD found no significant benefit of ICD compared to control among 1,040 patients with eGFR $<60 \mathrm{ml} / \mathrm{min}$ (adjusted HR 0.8 , 95\% CI 0.4-1.5). (83) (Figure 2) Among dialysis patients, multiple authors have reported increased mortality and increased complication rates in ICD recipients compared to ICD recipients without CKD. (84-86) An often overlooked complication of ICDs important to CKD management is the potential for intravascular leads to promote central venous stenosis, vascular access compromise and an increased risk of blood stream infections. (87) A recent study examined 9,528 hemodialysis patients enrolled in the Medicare program who received a defibrillator device between 1994-2006. (88) Annual mortality was disturbingly high at $45 \%$, and the majority of deaths were attributed to arrhythmic causes (38\%). The rate of infection was also alarming, with high annual rates of bacteremia (52\%) and device infection (4.2\%). This study also highlighted the growing number of dialysis patients who receive primary prevention ICDs in the absence of trial data supporting efficacy in this population. The study also compared survival of hemodialysis patients receiving a secondary prevention ICD (i.e. after sustaining and surviving a cardiac arrest) with a propensity matched control group. This analysis revealed a significant overall survival advantage associated with ICD implantation (HR 0.86), although the benefit did not extend past 3 years. Even though this analysis is subject to bias by indication, it corroborates previous findings suggesting a modest survival benefit with secondary prevention ICDs. (89) Newer leadless defibrillator devices such as the subcutaneous implantable defibrillator and wearable external defibrillator may be especially advantageous among dialysis patients to avoid vascular complications and minimize infectious risks.

In the absence of randomized trial data that specifically addresses the efficacy of ICD therapy in the CKD population, increased communication between nephrologists and cardiologists is needed to counsel potential ICD recipients about the likelihood of increased risks and reduced benefits compared to estimates obtained from the general population, and coordinate ICD placement when indicated to reduce the possibilities of vascular access compromise.

A summary of potential preventative strategies for patients at high risk for SCD is listed in Table 1. 


\section{Conclusion}

SCD is a major problem in CKD patients, and our understanding of this disease is underdeveloped. Well-designed cohort studies will be needed to understand basic understanding of disease pathophysiology and risk factors, and randomized intervention trials will be needed before new and effective management practices can be developed. Based on current evidence, a common sense approach to SCD prevention would be to target patients at highest risk for treatment with existing cardiovascular medications and reduce and monitor potential dialysis-related arrhythmic triggers for ESKD patients maintained on hemodialysis. Other therapies such as more frequent dialysis modalities and ICDs should be used judiciously and on a case-by-case basis, with recognition of the associated hazards that these approaches carry in the vulnerable population of patients with CKD.

\section{Acknowledgments}

The author is supported by research grant K23DK098281 from the National Institutes of Health, National Institute of Diabetes and Digestive and Kidney Diseases.

\section{References}

1. Herzog CA, Asinger RW, Berger AK, et al. Cardiovascular disease in chronic kidney disease. A clinical update from Kidney Disease: Improving Global Outcomes (KDIGO). Kidney Int. 2011; 80:572-586. [PubMed: 21750584]

2. Pun PH, Smarz TR, Honeycutt EF, Shaw LK, Al-Khatib SM, Middleton JP. Chronic kidney disease is associated with increased risk of sudden cardiac death among patients with coronary artery disease. Kidney Int. 2009; 76:652-658. [PubMed: 19536082]

3. Goldenberg I, Moss AJ, McNitt S, et al. Relations among renal function, risk of sudden cardiac death, and benefit of the implanted cardiac defibrillator in patients with ischemic left ventricular dysfunction. Am J Cardiol. 2006; 98:485-490. [PubMed: 16893702]

4. Saxon LA, Bristow MR, Boehmer J, et al. Predictors of sudden cardiac death and appropriate shock in the Comparison of Medical Therapy, Pacing, and Defibrillation in Heart Failure (COMPANION) Trial. Circulation. 2006; 114:2766-2772. [PubMed: 17159063]

5. Deo R, Lin F, Vittinghoff E, Tseng ZH, Hulley SB, Shlipak MG. Kidney Dysfunction and Sudden Cardiac Death Among Women With Coronary Heart Disease. Hypertension. 2008

6. Deo R, Sotoodehnia N, Katz R, et al. Cystatin C and sudden cardiac death risk in the elderly. Circ Cardiovasc Qual Outcomes. 3:159-164. [PubMed: 20233980]

7. USRDS Annual Data Report. National Institutes of Health, National Institute of Diabetes and Digestive and Kidney Diseases; Bethesda: 2005.

8. Herzog CA. Can we prevent sudden cardiac death in dialysis patients? Clin J Am Soc Nephrol. 2007; 2:410-412. [PubMed: 17699443]

9. USRDS Annual Data Report. National Institutes of Health, National Institute of Diabetes and Digestive and Kidney Diseases; Bethesda: 2010.

10. USRDS Annual Data Report. National Institutes of Health, National Institute of Diabetes and Digestive and Kidney Diseases; Bethesda: 2006.

11. Pun P, Lehrich RW, Smith SR, Middleton JP. Predictors of survival following cardiac arrest in outpatient hemodialysis clinics. Clin J Am Soc Nephrol. 2007; 2:491-500. [PubMed: 17699456]

12. Karnik JA, Young BS, Lew NL, et al. Cardiac arrest and sudden death in dialysis units. Kidney Int. 2001; 60:350-357. [PubMed: 11422771]

13. Lai M, Hung K, Huang J, Tsai T. Clinical findings and outcomes of intra-hemodialysis cardiopulmonary resuscitation. Am J Nephrol. 1999; 19:468-473. [PubMed: 10460936]

14. Moss AH, Holley JL, Upton MB. Outcomes of cardiopulmonary resuscitation in dialysis patients. J Am Soc Nephrol. 1992; 3:1238-1243. [PubMed: 1477319] 
15. Eknoyan G, Beck GJ, Cheung AK, et al. Effect of dialysis dose and membrane flux in maintenance hemodialysis. N Engl J Med. 2002; 347:2010-2019. [PubMed: 12490682]

16. Wanner C, Krane V, Marz W, et al. Atorvastatin in patients with type 2 diabetes mellitus undergoing hemodialysis. N Engl J Med. 2005; 353:238-248. [PubMed: 16034009]

17. Parekh RS, Plantinga LC, Kao WH, et al. The association of sudden cardiac death with inflammation and other traditional risk factors. Kidney Int. 2008; 74:1335-1342. [PubMed: 18769368]

18. Wang AY, Lam CW, Chan IH, Wang M, Lui SF, Sanderson JE. Sudden cardiac death in end-stage renal disease patients: a 5-year prospective analysis. Hypertension. 56:210-216. [PubMed: 20606110]

19. Jadoul M, Thumma J, Fuller DS, et al. Modifiable practices associated with sudden death among hemodialysis patients in the Dialysis Outcomes and Practice Patterns Study. Clinical journal of the American Society of Nephrology: CJASN. 2012; 7:765-774. [PubMed: 22403271]

20. Myerburg, RJCA. Cardiac arrst and sudden cardiac death.: Braunwald's heart disease A textbook of cardiovascular medicine. Elsevier Saunders; Philadelphia: 2005.

21. Pratt CM, Greenway PS, Schoenfeld MH, Hibben ML, Reiffel JA. Exploration of the precision of classifying sudden cardiac death. Implications for the interpretation of clinical trials. Circulation. 1996; 93:519-524. [PubMed: 8565170]

22. Zipes DP, Camm AJ, Borggrefe M, et al. ACC/AHA/ESC 2006 Guidelines for Management of Patients With Ventricular Arrhythmias and the Prevention of Sudden Cardiac Death: a report of the American College of Cardiology/American Heart Association Task Force and the European Society of Cardiology Committee for Practice Guidelines (writing committee to develop Guidelines for Management of Patients With Ventricular Arrhythmias and the Prevention of Sudden Cardiac Death): developed in collaboration with the European Heart Rhythm Association and the Heart Rhythm Society. Circulation. 2006; 114:e385-484. [PubMed: 16935995]

23. Ritz E, Wanner C. The challenge of sudden death in dialysis patients. Clinical Journal Of The American Society Of Nephrology. 2008; 3:920-929. [PubMed: 18372318]

24. Herzog CA. Cardiac arrest in dialysis patients: approaches to alter an abysmal outcome. Kidney Int Suppl. 2003:S197-200. [PubMed: 12694343]

25. Bleyer AJ, Hartman J, Brannon PC, Reeves-Daniel A, Satko SG, Russell G. Characteristics of sudden death in hemodialysis patients. Kidney Int. 2006; 69:2268-2273. [PubMed: 16672908]

26. Huikuri HV, Castellanos A, Myerburg RJ. Sudden death due to cardiac arrhythmias. N Engl J Med. 2001; 345:1473-1482. [PubMed: 11794197]

27. Bayes de Luna A, Coumel P, Leclercq JF. Ambulatory sudden cardiac death: mechanisms of production of fatal arrhythmia on the basis of data from 157 cases. Am Heart J. 1989; 117:151159. [PubMed: 2911968]

28. Ohtake T, Kobayashi S, Moriya H, et al. High prevalence of occult coronary artery stenosis in patients with chronic kidney disease at the initiation of renal replacement therapy: an angiographic examination. J Am Soc Nephrol. 2005; 16:1141-1148. [PubMed: 15743997]

29. London GM, Guerin AP, Marchais SJ, Metivier F, Pannier B, Adda H. Arterial media calcification in end-stage renal disease: impact on all-cause and cardiovascular mortality. Nephrol Dial Transplant. 2003; 18:1731-1740. [PubMed: 12937218]

30. Lowrie EG, Lew NL. Death risk in hemodialysis patients: the predictive value of commonly measured variables and an evaluation of death rate differences between facilities. Am J Kidney Dis. 1990; 15:458-482. [PubMed: 2333868]

31. Kalantar-Zadeh K, Block G, Humphreys MH, Kopple JD. Reverse epidemiology of cardiovascular risk factors in maintenance dialysis patients. Kidney Int. 2003; 63:793-808. [PubMed: 12631061]

32. Zager PG, Nikolic J, Brown RH, et al. Medical Directors of Dialysis Clinic, Inc. "U” curve association of blood pressure and mortality in hemodialysis patients. Kidney Int. 1998; 54:561569. [PubMed: 9690224]

33. Yamada S, Ishii H, Takahashi H, et al. Prognostic value of reduced left ventricular ejection fraction at start of hemodialysis therapy on cardiovascular and all-cause mortality in end-stage renal disease patients. Clinical journal of the American Society of Nephrology: CJASN. 2010; 5:17931798. [PubMed: 20595691] 
34. Park M, Hsu CY, Li Y, et al. Associations between kidney function and subclinical cardiac abnormalities in CKD. J Am Soc Nephrol. 2012; 23:1725-1734. [PubMed: 22935481]

35. Pun PH, Smarz TR, Honeycutt EF, Shaw LK, Al-Khatib SM, Middleton JP. Chronic kidney disease is associated with increased risk of sudden cardiac death among patients with coronary artery disease. Kidney Int. 2009; 76:652-658. [PubMed: 19536082]

36. Mangrum AJ, Liu D, Dimarco JP, Bolton K, Mangrum M. Sudden Cardiac Death and Left Ventricular Function in Hemodialysis Patients. Heart Rhythm. 2005; 2:S41.

37. Paoletti E, Specchia C, Di Maio G, et al. The worsening of left ventricular hypertrophy is the strongest predictor of sudden cardiac death in haemodialysis patients: a 10 year survey. Nephrol Dial Transplant. 2004; 19:1829-1834. [PubMed: 15128888]

38. Mark PB, Johnston N, Groenning BA, et al. Redefinition of uremic cardiomyopathy by contrastenhanced cardiac magnetic resonance imaging. Kidney Int. 2006; 69:1839-1845. [PubMed: 16508657]

39. Schietinger BJ, Brammer GM, Wang $\mathrm{H}$, et al. Patterns of late gadolinium enhancement in chronic hemodialysis patients. JACC Cardiovasc Imaging. 2008; 1:450-456. [PubMed: 19356466]

40. Amann K, Breitbach M, Ritz E, Mall G. Myocyte/capillary mismatch in the heart of uremic patients. J Am Soc Nephrol. 1998; 9:1018-1022. [PubMed: 9621284]

41. Amann K, Ritz E, Wiest G, Klaus G, Mall G. A role of parathyroid hormone for the activation of cardiac fibroblasts in uremia. J Am Soc Nephrol. 1994; 4:1814-1819. [PubMed: 8068880]

42. Burton JO, Jefferies HJ, Selby NM, McIntyre CW. Hemodialysis-induced cardiac injury: determinants and associated outcomes. Clin J Am Soc Nephrol. 2009; 4:914-920. [PubMed: 19357245]

43. Foley RN, Gilbertson DT, Murray T, Collins AJ. Long interdialytic interval and mortality among patients receiving hemodialysis. N Engl J Med. 2011; 365:1099-1107. [PubMed: 21992122]

44. Pun PH, Lehrich RW, Honeycutt EF, Herzog CA, Middleton JP. Modifiable risk factors associated with sudden cardiac arrest within hemodialysis clinics. Kidney Int. 2010

45. Movilli E, Gaggia P, Zubani R, et al. Association between high ultrafiltration rates and mortality in uraemic patients on regular haemodialysis. A 5-year prospective observational multicentre study. Nephrol Dial Transplant. 2007; 22:3547-3552. [PubMed: 17890254]

46. Saran R, Bragg-Gresham JL, Levin NW, et al. Longer treatment time and slower ultrafiltration in hemodialysis: associations with reduced mortality in the DOPPS. Kidney Int. 2006; 69:12221228. [PubMed: 16609686]

47. Flythe JE, Brunelli SM. The risks of high ultrafiltration rate in chronic hemodialysis: implications for patient care. Semin Dial. 2011; 24:259-265. [PubMed: 21480996]

48. Morris ST, Galiatsou E, Stewart GA, Rodger RS, Jardine AG. QT dispersion before and after hemodialysis. J Am Soc Nephrol. 1999; 10:160-163. [PubMed: 9890322]

49. Beaubien ER, Pylypchuk GB, Akhtar J, Biem HJ. Value of corrected QT interval dispersion in identifying patients initiating dialysis at increased risk of total and cardiovascular mortality. Am J Kidney Dis. 2002; 39:834-842. [PubMed: 11920351]

50. Gabutti L, Ferrari N, Giudici G, Mombelli G, Marone C. Unexpected haemodynamic instability associated with standard bicarbonate haemodialysis. Nephrol Dial Transplant. 2003; 18:23692376. [PubMed: 14551368]

51. Di Iorio B, Torraca S, Piscopo C, et al. Dialysate bath and QTc interval in patients on chronic maintenance hemodialysis: pilot study of single dialysis effects. J Nephrol. 2012; 25:653-660. [PubMed: 21983985]

52. Pande SR,R, Bloom E, Chewaproug D, Dissanayake I. Effect of dialysate baths on serum bicarbonate levels in hemodialysis patients. Am J Kidney Dis. 2011; 57:A75.

53. Tentori F, Karaboyas A, Robinson BM, et al. Association of dialysate bicarbonate concentration with mortality in the Dialysis Outcomes and Practice Patterns Study (DOPPS). Am J Kidney Dis. 2013; 62:738-746. [PubMed: 23707043]

54. Hayes J, Kalantar-Zadeh K, Lu JL, Turban S, Anderson JE, Kovesdy CP. Association of hypo- and hyperkalemia with disease progression and mortality in males with chronic kidney disease: the role of race. Nephron Clin Pract. 2012; 120:c8-16. [PubMed: 22156587] 
55. Spooner PM. Sudden cardiac death: The larger problem... The larger genome. J Cardiovasc Electrophysiol. 2009; 20:585-596. [PubMed: 19207788]

56. Bonato FO, Lemos MM, Cassiolato JL, Canziani ME. Prevalence of ventricular arrhythmia and its associated factors in nondialyzed chronic kidney disease patients. PLoS One. 2013; 8:e66036. [PubMed: 23762460]

57. Wan C, Herzog CA, Zareba W, Szymkiewicz SJ. Sudden Cardiac Arrest in Hemodialysis Patients with Wearable Cardioverter Defibrillator. Ann Noninvasive Electrocardiol. 2013

58. Hsueh C-HC, Neal X, Chen Peng-Sheng, Lin Shien F, Moe Sharon M. Increased Inducibility of Ventricular Arrhythmia in a Rat Model of Chronic Kidney Disease. J Am Soc Nephrol. 2013; 24:139A.

59. Davis TR, Young BA, Eisenberg MS, Rea TD, Copass MK, Cobb LA. Outcome of cardiac arrests attended by emergency medical services staff at community outpatient dialysis centers. Kidney Int. 2008; 73:933-939. [PubMed: 18172435]

60. Takeda K, Harada A, Okuda S, et al. Sudden death in chronic dialysis patients. Nephrol Dial Transplant. 1997; 12:952-955. [PubMed: 9175048]

61. Pun PH, Schumm D, Sanders GD, et al. A pilot study using an implantable device to characterize cardiac arrhythmias in hemodialysis patients: implications for future research. Ann Noninvasive Electrocardiol. 2012; 17:159. [PubMed: 22537338]

62. Lehrich R, Pun PH, Tanenbaum ND, Smith SR, Middleton JP. Automated External Defibrillators and Survival from Cardiac Arrest in the Outpatient Hemodialysis Clinic. J Am Soc Nephrol. 2007; 18:312-320. [PubMed: 17151332]

63. Drechsler C, Krane V, Winkler K, Dekker FW, Wanner C. Changes in adiponectin and the risk of sudden death, stroke, myocardial infarction, and mortality in hemodialysis patients. Kidney Int. 2009; 76:567-575. [PubMed: 19516245]

64. Pun PH, Lehrich RW, Honeycutt EF, Herzog CA, Middleton JP. Modifiable risk factors associated with sudden cardiac arrest within hemodialysis clinics. Kidney Int. 2011; 79:218-227. [PubMed: 20811332]

65. Shastri S, Tangri N, Tighiouart H, et al. Predictors of sudden cardiac death: a competing risk approach in the hemodialysis study. Clinical journal of the American Society of Nephrology: CJASN. 2012; 7:123-130. [PubMed: 22076880]

66. Passman R, Herzog CA. End-stage renal disease: sudden cardiac death: stratifying risk in dialysis patients. Nat Rev Nephrol. 2011; 7:133-135. [PubMed: 21151208]

67. Ganesh SK, Stack AG, Levin NW, Hulbert-Shearon T, Port FK. Association of elevated serum $\mathrm{PO}(4), \mathrm{Ca} \times \mathrm{PO}(4)$ product, and parathyroid hormone with cardiac mortality risk in chronic hemodialysis patients. J Am Soc Nephrol. 2001; 12:2131-2138. [PubMed: 11562412]

68. Cice G, Ferrara L, D’Andrea A, et al. Carvedilol increases two-year survivalin dialysis patients with dilated cardiomyopathy: a prospective, placebo-controlled trial. J Am Coll Cardiol. 2003; 41:1438-1444. [PubMed: 12742278]

69. Tangri N, Shastri S, Tighiouart H, et al. Beta-Blockers for Prevention of Sudden Cardiac Death in Patients on Hemodialysis: A Propensity Score Analysis of the HEMO Study. Am J Kidney Dis. 2011

70. Agarwal R, Sinha AD, Pappas MK, Abraham TN, Tegegne GG. Hypertension in hemodialysis patients treated with atenolol or lisinopril: a randomized controlled trial. Nephrol Dial Transplant. 2014

71. Baigent C, Landray MJ, Reith C, et al. The effects of lowering LDL cholesterol with simvastatin plus ezetimibe in patients with chronic kidney disease (Study of Heart and Renal Protection): a randomised placebo-controlled trial. Lancet. 2011; 377:2181-2192. [PubMed: 21663949]

72. Fellstrom BC, Jardine AG, Schmieder RE, et al. Rosuvastatin and cardiovascular events in patients undergoing hemodialysis. N Engl J Med. 2009; 360:1395-1407. [PubMed: 19332456]

73. Mann JF, Gerstein HC, Pogue J, Bosch J, Yusuf S. Renal insufficiency as a predictor of cardiovascular outcomes and the impact of ramipril: the HOPE randomized trial. Ann Intern Med. 2001; 134:629-636. [PubMed: 11304102] 
74. Brenner BM, Cooper ME, de Zeeuw D, et al. Effects of losartan on renal and cardiovascular outcomes in patients with type 2 diabetes and nephropathy. N Engl J Med. 2001; 345:861-869. [PubMed: 11565518]

75. Iseki K, Arima H, Kohagura K, et al. Effects of angiotensin receptor blockade (ARB) on mortality and cardiovascular outcomes in patients with long-term haemodialysis: a randomized controlled trial. Nephrol Dial Transplant. 2013; 28:1579-1589. [PubMed: 23355629]

76. Zannad F, Kessler M, Lehert P, et al. Prevention of cardiovascular events in end-stage renal disease: results of a randomized trial of fosinopril and implications for future studies. Kidney Int. 2006; 70:1318-1324. [PubMed: 16871247]

77. Tai DJ, Lim TW, James MT, Manns BJ, Tonelli M, Hemmelgarn BR. Cardiovascular effects of angiotensin converting enzyme inhibition or angiotensin receptor blockade in hemodialysis: a meta-analysis. Clinical journal of the American Society of Nephrology: CJASN. 2010; 5:623-630. [PubMed: 20133488]

78. Santoro A, Mancini E, London G, et al. Patients with complex arrhythmias during and after haemodialysis suffer from different regimens of potassium removal. Nephrol Dial Transplant. 2008; 23:1415-1421. [PubMed: 18065796]

79. Pun PH, Horton JR, Middleton JP. Dialysate calcium concentration and the risk of sudden cardiac arrest in hemodialysis patients. Clinical journal of the American Society of Nephrology: CJASN. 2013; 8:797-803. [PubMed: 23371957]

80. Mendoza JM, Bayes LY, Sun S, Doss S, Schiller B. Effect of Lowering Dialysate Sodium Concentration on Interdialytic Weight Gain and Blood Pressure in Patients Undergoing ThriceWeekly In-center Nocturnal Hemodialysis: A Quality Improvement Study. Am J Kidney Dis. 2011

81. Jefferies HJ, Burton JO, McIntyre CW. Individualised dialysate temperature improves intradialytic haemodynamics and abrogates haemodialysis-induced myocardial stunning, without compromising tolerability. Blood Purif. 2011; 32:63-68. [PubMed: 21346338]

82. In-Center Hemodialysis Six Times per Week versus Three Times per Week. New England Journal of Medicine. 2010; 363:2287-2300. [PubMed: 21091062]

83. Pun PH, Al-Khatib SM, Han JY, et al. Implantable Cardioverter-Defibrillators for Primary Prevention of Sudden Cardiac Death in CKD: A Meta-analysis of Patient-Level Data From 3 Randomized Trials. Am J Kidney Dis. 2014

84. Sakhuja R, Keebler M, Lai TS, McLaughlin Gavin C, Thakur R, Bhatt DL. Meta-analysis of mortality in dialysis patients with an implantable cardioverter defibrillator. Am J Cardiol. 2009; 103:735-741. [PubMed: 19231344]

85. Dasgupta A, Montalvo J, Medendorp S, et al. Increased complication rates of cardiac rhythm management devices in ESRD patients. Am J Kidney Dis. 2007; 49:656-663. [PubMed: 17472848]

86. Wase A, Basit A, Nazir R, et al. Impact of chronic kidney disease upon survival among implantable cardioverter-defibrillator recipients. J Interv Card Electrophysiol. 2004; 11:199-204. [PubMed: 15548886]

87. Drew DA, Meyer KB, Weiner DE. Transvenous cardiac device wires and vascular access in hemodialysis patients. Am J Kidney Dis. 2011; 58:494-496. [PubMed: 21664734]

88. Charytan DM, Patrick AR, Liu J, et al. Trends in the use and outcomes of implantable cardioverterdefibrillators in patients undergoing dialysis in the United States. Am J Kidney Dis. 2011; 58:409417. [PubMed: 21664735]

89. Herzog CA, Li S, Weinhandl ED, Strief JW, Collins AJ, Gilbertson DT. Survival of dialysis patients after cardiac arrest and the impact of implantable cardioverter defibrillators. Kidney Int. 2005; 68:818-825. [PubMed: 16014061]

90. Pun PH, Middleton JP. Sudden cardiac death in hemodialysis patients: a comprehensive care approach to reduce risk. Blood Purif. 2012; 33:183-189. [PubMed: 22269796] 


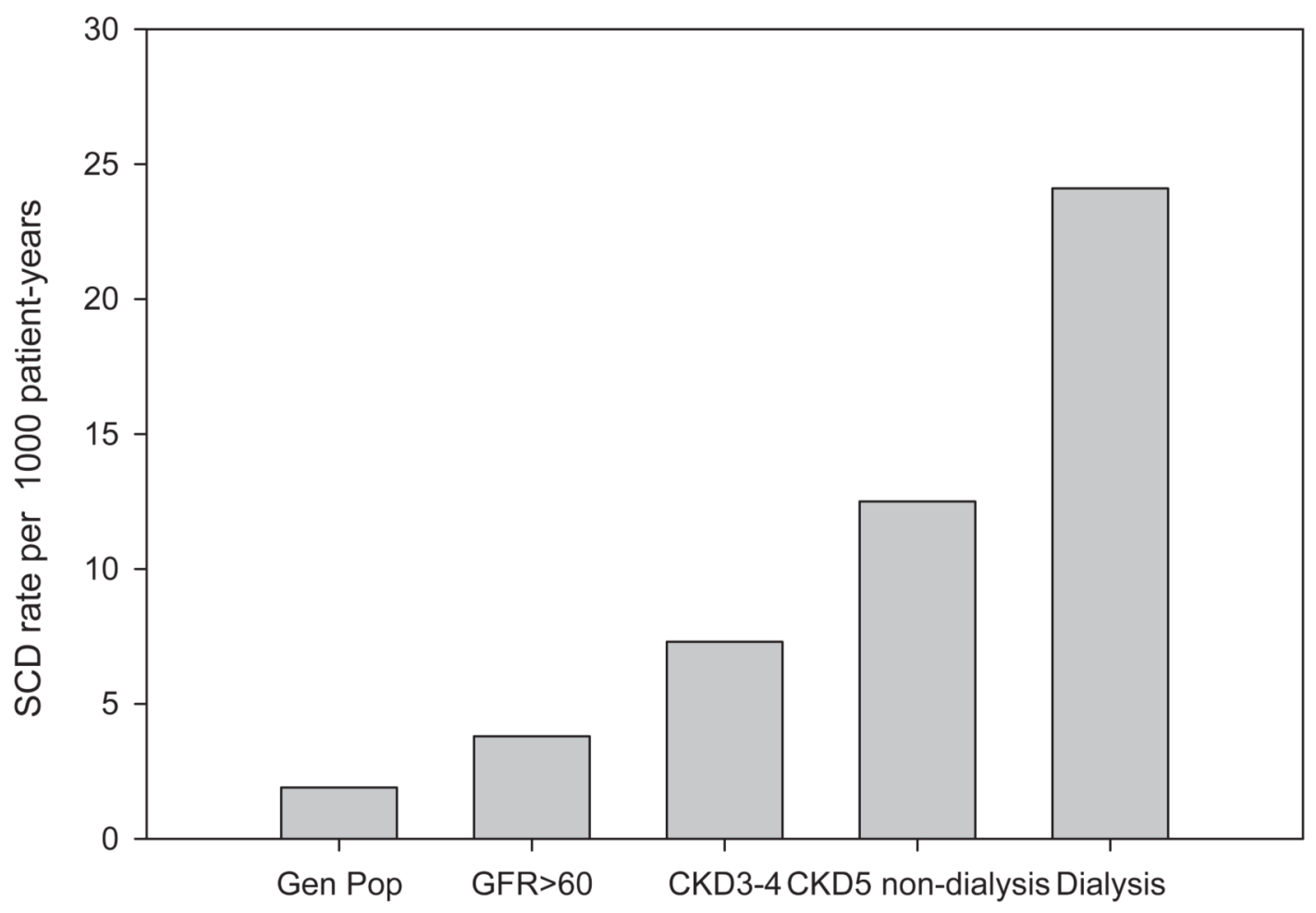

Figure 1.

Risk of sudden cardiac death by glomerular filtration rate among 19,440 subjects with significant coronary artery disease. (2) 


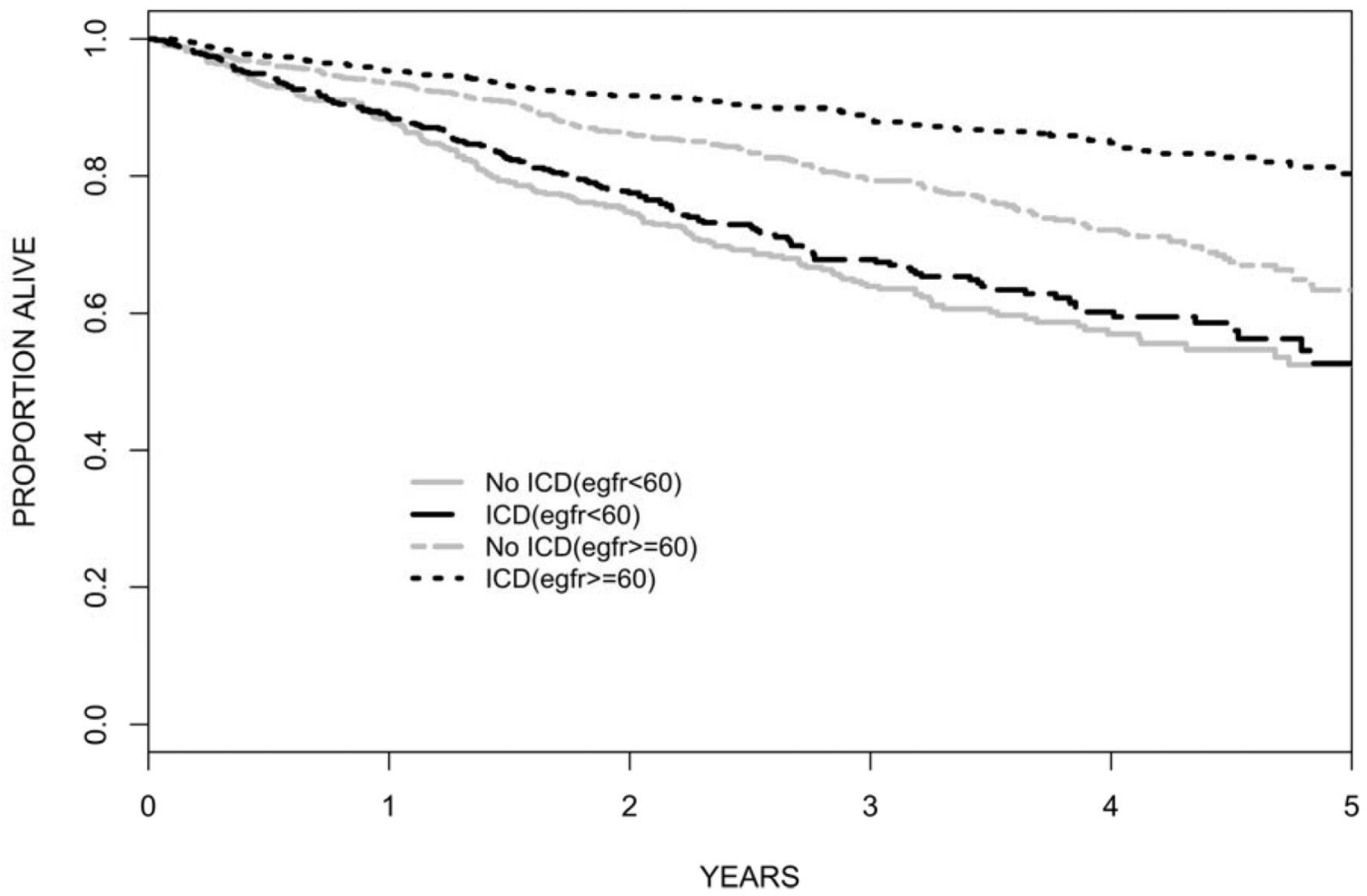

Figure 2.

Kaplan-Meier Survival Curves in ICD Recipients vs. Non-recipients According to eGFR. Unadjusted HR for mortality benefit of ICD: eGFR>=60 HR=0.53, 95\% CI 0.42-0.67; eGFR $<60 \mathrm{HR}=0.92,95 \%$ CI 0.74-1.14. (83) 
Table 1

Possible Strategies for SCD Management in High Risk CKD Patients. (adapted from Pun et. al (90))

\begin{tabular}{|c|c|}
\hline Strategy & Possible Intervention \\
\hline \multicolumn{2}{|l|}{ Manage Underlying Cardiomyopathy } \\
\hline \multirow[t]{2}{*}{ Systolic Heart Dysfunction } & $\begin{array}{l}\text { Assess left ventricular systolic and } \\
\text { diastolic function within } 3 \text { months of } \\
\text { dialysis initiation and every } 3 \text { years } \\
\text { thereafter }\end{array}$ \\
\hline & $\begin{array}{l}\text { Use carvedilol in patients with } \\
\text { dilated cardiomyopathy }\end{array}$ \\
\hline $\begin{array}{l}\text { Diastolic Heart Dysfunction (Left } \\
\text { Ventricular Hypertrophy) }\end{array}$ & $\begin{array}{l}\text { Consider frequent hemodialysis to } \\
\text { reduce left ventricular mass; } \\
\text { consider the use of angiotensin } \\
\text { converting enzyme inhibitors or } \\
\text { angiotensin receptor blockers }\end{array}$ \\
\hline \multicolumn{2}{|l|}{ Minimize Arrhythmic Triggers } \\
\hline \multirow[t]{2}{*}{ Potassium shifts } & $\begin{array}{l}\text { Monitor potassium more frequently } \\
\text { especially after hospitalization, and } \\
\text { change dialysis prescription } \\
\text { accordingly }\end{array}$ \\
\hline & $\begin{array}{l}\text { Avoid low }(<2 \mathrm{meq} / \mathrm{L}) \text { potassium } \\
\text { baths. }\end{array}$ \\
\hline Calcium shifts & $\begin{array}{l}\text { Avoid low calcium baths, especially } \\
\text { in the context of concurrent use of } \\
\text { QT prolonging medications }\end{array}$ \\
\hline Metabolic Alkalosis & $\begin{array}{l}\text { Account for acetate in dialysis acid } \\
\text { concentrate to determine total } \\
\text { buffer; avoid high dialysate } \\
\text { bicarbonate concentrations in } \\
\text { patients who are alkalotic. }\end{array}$ \\
\hline \multirow[t]{3}{*}{ Rapid Ultrafiltration } & $\begin{array}{l}\text { Encourage patient compliance with } \\
\text { fluid restriction between treatments. }\end{array}$ \\
\hline & $\begin{array}{l}\text { Avoid sodium ramping and large } \\
\text { dialysate/serum sodium gradients }\end{array}$ \\
\hline & $\begin{array}{l}\text { Extend dialysis time to reduce } \\
\text { ultrafiltration rate }\end{array}$ \\
\hline Dialysis-induced myocardial ischemia & Cool dialysate temperature \\
\hline \multicolumn{2}{|l|}{$\begin{array}{l}\text { Weigh benefits and risks of } \\
\text { Implantable Cardioverter Defibrillators }\end{array}$} \\
\hline & $\begin{array}{l}\text { Consider secondary prevention } \\
\text { ICDs after cardiac arrest }\end{array}$ \\
\hline & $\begin{array}{l}\text { Additional data needed to support } \\
\text { primary prevention ICD among } \\
\text { patients with eGFR }<60 \mathrm{ml} / \mathrm{min} / \mathrm{m}^{2}\end{array}$ \\
\hline & $\begin{array}{l}\text { Increase coordination between } \\
\text { nephrologists and cardiologists to } \\
\text { consider vascular and infectious } \\
\text { risks, especially among ESKD } \\
\text { patients and patients at high risk of } \\
\text { CKD progression }\end{array}$ \\
\hline
\end{tabular}

